Article

\title{
Estimation of Source-Based Aerosol Optical Properties for Polydisperse Aerosols from Receptor Models
}

\author{
Chang Hoon Jung ${ }^{1, *(\mathbb{D})}$, Ji Yi Lee ${ }^{2}$, Junshik Um ${ }^{3} \mathbb{D}$, Seoung Soo Lee ${ }^{4}$, Young Jun Yoon ${ }^{5}$ and \\ Yong Pyo Kim ${ }^{6}$
}

1 Department of Health Management, Kyungin Women's University, 101 Gesan-gil, Gyeyang-gu, Incheon 21041, Korea

2 Department of Environmental Science and Engineering, Ewha Womans University, 11-1 Daehyun-dong, Seodaemun-gu, Seoul 03760, Korea; yijiyi@ewha.ac.kr

3 Department of Atmospheric Sciences, Pusan National University, 2, Busandaehak-ro 63beon-gil, Geumjeong-gu, Busan 46241, Korea; jjunum@pusan.ac.kr

4 Earth System Science Interdisciplinary Center, University of Maryland, College Park, MD 20740, USA; cumuluss@gmail.com

5 Korea Polar Research Institute, 26, Songdomirae-ro, Yeonsu-gu, Incheon 21990, Korea; yjyoon@kopri.re.kr

6 Department of Chemical Engineering and Material Science, Ewha Womans University, 11-1 Daehyun-dong, Seodaemun-gu, Seoul 03760, Korea; yong@ewha.ac.kr

* Correspondence: jch@kiwu.ac.kr; Tel.: +82-32-540-0166

Received: 10 February 2019; Accepted: 1 April 2019; Published: 6 April 2019

\begin{abstract}
We estimated source-based aerosol optical properties for polydisperse aerosols according to a chemical-species-resolved mass contribution method based on source apportionment. We investigated the sensitivity of aerosol optical properties based on PM2.5 (particulate matter that have a diameter of less than 2.5 micrometers) monitoring results. These aerosols were composed of ions, metals, elemental carbon, and water-soluble organic carbon which includes humic-like carbon substances and water-soluble organic carbon. We calculated aerosols' extinction coefficients based on the PM2.5 composition data and the results of a multivariate receptor model (Solver for Mixture Problem model, SMP). Based on the mass concentration of chemical composition and nine sources calculated with the SMP receptor model, we estimated the size-resolved mass extinction efficiencies for each aerosol source using a multilinear regression model. Consequently, this study quantitatively determined the size resolved sources contributing to the apportionment-based aerosol optical properties and calculated their respective contributions. The results show that source-resolved mass concentrations and extinction coefficients had varying contributions. This discrepancy between the source-based mass concentration and extinction coefficient was mainly due to differences between the source-dependent aerosol size distribution and the aerosol optical properties from different sources.
\end{abstract}

Keywords: mass extinction efficiency; SMP receptor model; size- and source-resolved aerosol optical properties; polydispersity

\section{Introduction}

Atmospheric aerosols originate from a wide variety of natural and anthropogenic sources. A combination of various sources and physical and chemical processes generates these atmospheric aerosols. The optical properties of atmospheric aerosols play a key role in earth's radiation budget. They depend on size distribution, chemical composition, mass concentration, density, and wavelength. These optical properties are represented by the refractive index. For example, aerosol scattering is 
related to the real refractive index, and aerosol light absorption is related to the imaginary refractive index, and the refractive index depends on the above-mentioned conditions [1]. On the basis of the physical and chemical processes that generate aerosols, different source types can be distinguished. Knowledge of atmospheric aerosol optical characteristics depending on the source, such as aerosol extinction, scattering, and absorption, is necessary to enhance our understanding of how atmospheric aerosols impact the climate.

Among many parameters that represent the optical properties of aerosols, the mass extinction efficiency (MEE) is a key index to estimate the aerosol extinction coefficient [2]. The MEE is the summation of the mass scattering efficiency (MSE) and mass absorption efficiency (MAE). Here, the MEE, MSE, and MAE are mass-related optical constants that are related to the specific masses and densities of aerosol components.

These mass efficiencies (MEE, MSA, and MAE) are based on aerosol composition and are a function of the physico-chemical characteristics of aerosols, such as the aerosol refractive index and size distribution. However, for convenience, mass efficiencies are conventionally treated as constants [3]. According to Horvath [4], the MAE also depends on particle size. The conventionally used MAE of $10 \mathrm{~m}^{2} \mathrm{~g}^{-1}$ for elemental carbon (EC) is applicable to monodisperse carbon particles with radii of $0.08 \mu \mathrm{m}$. For particle sizes larger than a few micrometers, the MAE of EC decreases to below $1 \mathrm{~m}^{2} \mathrm{~g}^{-1}$, which indicates that size distribution is an important factor to determine aerosol optical properties, such as mass efficiencies.

Another important approach to understand aerosol characteristics is to investigate their sources. Source-based analysis provides important information to understand not only the characteristics, but also where emissions come from. The receptor model can provide contribution estimates for each source based on composition-dependent mass concentration. Receptor-oriented models infer source contributions by determining the best-fit linear combination between the emission source chemical composition profiles needed to reconstruct the measured chemical composition of ambient samples [5].

Although receptor models are able to show source-based mass concentrations and contributions, their source-based optical properties may have different contributions. These optical properties and the respective refractive indices depend on size distribution, chemical composition, and concentration of each source.

For this reason, source-based optical properties, such as the source-based MEE, require consideration of their source-based mass concentrations and contributions, especially for polydisperse aerosol size distributions. A number of studies have investigated the optical properties of aerosols that are both size- and composition-dependent [6-9]. However, owing to their complexity, studies that analyze the dependency of aerosol optical properties on both particle size and source are rare [10-12]. Generally, two types of receptor models, the Chemical Mass Balance (CMB) and Positive Matrix Factorization (PMF) models, have been widely used in the area of source apportionment studies of air pollution. Since PMF is a multivariate factor analysis tool that decomposes a matrix of speciated sample data into two matrices (factor contributions and factor profiles), source profiles are not necessary to run it [13].

Recently, a new type of multivariate receptor model, the Solver for Mixture Problem (SMP) was developed. The SMP uses primal-dual path following interior-point quadratic programming by implementing five fundamental natural physical constraints. The SMP was used to apply error-free data to examine if estimated results satisfied all of these five fundamental natural physical constraints. Compared with other receptor models, the SMP can be adopted for the non-linear programming method. It allows any type of physical constraint to be easily implemented into the model as equality or inequality constraints. Thus, it has advantages over the other models utilized in aerosol apportionment [14].

In this study, we estimated the source-based MEE for polydisperse aerosols from the results of a source apportionment-based chemical-species-resolved mass contribution method. On the basis of the mass concentrations of inorganic ions, $\mathrm{EC}$, organic matter $(\mathrm{OM}), \mathrm{NaCl}$, and crustal ions measured 
in Seoul, Korea, we calculated the sensitivity of the total aerosol extinction coefficient $\left(b_{\text {ext }}\right)$ using Mie theory for polydisperse aerosol by modifying size distribution assumptions. Here, OM was composed of water-soluble organic matter (WSOM), humic-like carbon substances (HULIS-C), and water-insoluble organic matter (WISOM). Subsequently, we estimated the size-resolved source-based MEEs using their source-based mass concentrations and contributions from the SMP receptor model [14]. We used the multilinear regression (MLR)- and Mie theory-based model to estimate and calculate the optical properties of polydisperse aerosols in relation to their source. To estimate the absorption properties of HULIS-C, we also tested the sensitivity of size-resolved, source-based HULIS-C MEEs by changing the imaginary refractive index of HULIS-C.

\section{Methods}

\subsection{Data}

We analyzed the one-year PM2.5 sampling data from a previous study [14], in which a detailed description of the sampling measurements can be found. In order to determine PM2.5 total mass and ion concentrations, $24 \mathrm{~h}$ PM2.5 data were collected on pre-weighted $47 \mathrm{~mm}$ Teflon filters (Zefluor ${ }^{\mathrm{TM}}$, Pall Corp., Port Washington, NY) using a low-volume (flow rate, $16.7 \mathrm{~L} \mathrm{~min}^{-1}$ ) sampler. This sampler was equipped with Teflon-coated aluminum cyclone on the rooftop of the Korea Institute of Science and Technology, located northeast of downtown Seoul, Korea $\left(37.603^{\circ} \mathrm{N}, 127.047^{\circ} \mathrm{E}\right.$, at $58 \mathrm{~m}$ above sea level). The PM2.5 was measured daily during a one-year period from October 2012 to September 2013. The PM2.5 mass concentrations, inorganic ions, EC, OM (composed of WSOC, WISOC, and HULIS-C), $\mathrm{NaCl}$, and crustal components were chemically analyzed.

On the basis of PM2.5 chemical species, composed of inorganic matter (ammonium, sulfate, and nitrate), carbonaceous organic matter, $\mathrm{NaCl}$, and crustal components, we applied the SMP model. The PM2.5 source apportionment results reported in Kim et al. [14] indicate the source-based mass concentration and their mass contributions.

Nine sources from both transported and local sources were identified: (1) transported secondary sources (TS), (2) local secondary sulfates (LS), (3) local secondary nitrates (LN), (4) gasoline (G), (5) diesel (D), (6) transported biomass burning (TBB), (7) local biomass burning (LBB), (8) fugitive soil dust (FSD), and (9) waste burning (WB). TS is closely related to $\mathrm{NH}_{4}{ }^{+}, \mathrm{NO}_{3}{ }^{-}, \mathrm{SO}_{4}{ }^{2-}$, and OM; $\mathrm{LS}$ to $\mathrm{NH}_{4}{ }^{+}$and $\mathrm{SO}_{4}{ }^{2-}$; $\mathrm{LN}$ to $\mathrm{NH}_{4}{ }^{+}, \mathrm{NO}_{3}{ }^{-}$; $\mathrm{G}$ to OM (water-soluble) and EC; D to OM (water-insoluble) and EC; TBB to OM and EC; LBB to OM (HULIS, water-insoluble); and FSD to the crustal component and OM [14]. Supplementary Figure S1 shows a comparison of the measured PM2.5 mass concentration with the SMP-estimated PM2.5 mass concentration, which was also described in Kim et al. [14]. As Figure S1a shows, the PM2.5 measurement data and SMP estimated data have good agreement without significant loss of accuracy, which confirms that the data are reliable. Supplementary Figure $\mathrm{S} 1 \mathrm{~b}$ also shows the comparison of the PM2.5 mass concentration with the extinction coefficient with geometric mean diameter $\left(\mathrm{d}_{\mathrm{g}}\right)$ of $0.1 \mu \mathrm{m}$ at geometric standard deviation (GSD) of 1.5. Generally, also these data are in good agreement, as shown in Supplementary Figure S1. A more detailed explanation and comparison of source-based mass contribution with source-based extinction coefficient $\left(b_{\text {ext }}\right)$ contribution will be given at Section 3.

\subsection{Extinction Coefficient $\left(b_{\text {ext }}\right)$ Calculations for Polydisperse Aerosols}

Generally, the contribution of aerosol optical properties (scattering and absorption) differ owing to the characteristics of each chemical compound. Figure 1 shows a schematic diagram of how to obtain source-based aerosol optical properties of polydisperse aerosol particles from the SMP model and Mie theory [15]. Three steps are required. First, size-resolved aerosol optical properties (aerosol extinction and the scattering and absorption coefficients) can be obtained on the basis of input variables such as the chemical-species-based mass concentration of the PM2.5 measurement, lognormally assumed aerosol size distribution, aerosol densities, and wavelength ( $550 \mathrm{~nm}$ in this study) using Mie theory. Second, 
the SMP receptor model can derive source-based mass concentrations. Third, from size-resolved aerosol mass extinction coefficients using Mie theory and source-based mass concentrations, sourceand size-resolved mass extinction efficiencies can be estimated using the MLR model [10].

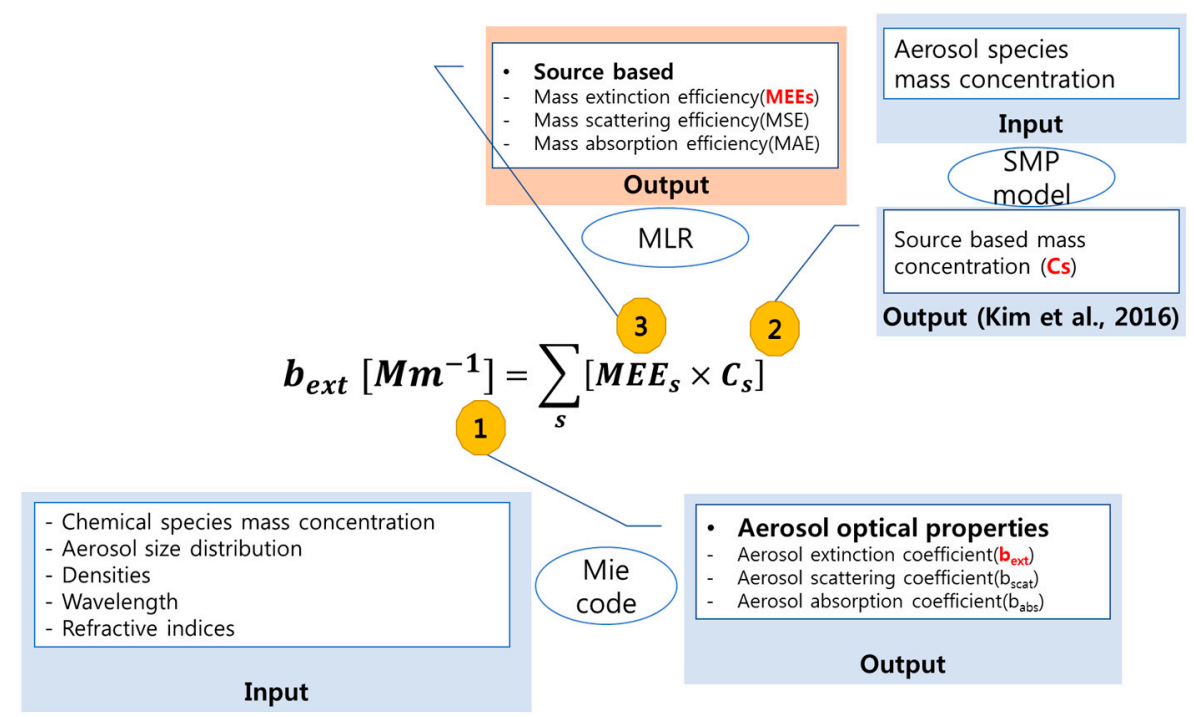

Figure 1. Schematic diagram showing the steps to calculate the source-based aerosol optical properties of polydisperse aerosols using the Solver for Mixture Problem (SMP) model and Mie theory.

As outlined above, the $b_{\text {ext }}$ value at a given size distribution was calculated with Mie theory, and the source-based MEE was calculated from the size-resolved $b_{\text {ext }}$ and source-based mass concentration. To calculate the aerosol extinction coefficient $\left(b_{\text {ext }}\right)$, the mass concentrations of inorganic ions, EC, OM (WSOM, HULIS, WISOM), $\mathrm{NaCl}$, and crustal component, as well as aerosol properties (size distributions, densities, refractive index) are necessary as input data. Here, we basically used the same refractive index for OM; only the HULIS refractive index was sensitively investigated. Table 1 lists the refractive indices at a wavelength of $550 \mathrm{~nm}$ and the densities of the various aerosol components used in this study [16-21]. We assumed a log-normal aerosol size distribution. An organic aerosol can be divided into water-soluble (HULIS and WSOC) and water-insoluble components. With these assumptions and initial data, we calculated the total aerosol extinction coefficient based on Mie theory. From the total $b_{\text {ext }}$ and total mass concentration, the MEE, MSE, and MAE were obtained under the assumption that the aerosol was internally mixed. Figure 2 shows the sensitivities of mass efficiencies (MEE, MSE, and MAE) as a function of the $d_{g}$ and the GSD of internally mixed aerosols. The $d_{g}$ of 0.1-2.5 $\mu \mathrm{m}$ and the GSD of 1.5-2.5 were considered. As shown in Figure 2, the calculated scattering, absorption, and extinction efficiencies had different values for the different GSDs and $d_{g}$. Generally, the mass efficiencies had a peak value around $d_{g}=0.3 \mu \mathrm{m}$ for a GSD of 1.5. However, the $d_{g}$ at which mass efficiencies had their maximum value decreased as the GSD increased. (Supplementary Figure $\mathrm{S} 2$ shows the sensitivity of the MEE for $\mathrm{EC}$, inorganic ion, $\mathrm{OM}, \mathrm{NaCl}$, and crustal aerosol.)

Table 1. Refractive indices and densities of externally mixed aerosols [16-18] at $\lambda=550 \mathrm{~nm}$.

\begin{tabular}{cccc}
\hline & $\mathbf{m}_{\mathbf{r}}$ & $\mathbf{m}_{\mathbf{i}}$ & Density $\left(\mathrm{g} \mathrm{cm}^{-3}\right)$ \\
\hline $\mathrm{EC}$ & 1.75 & 0.44 & 1.00 \\
Inorganic ions & 1.43 & 0.00 & 1.7 \\
$\mathrm{OM}$ & 1.53 & 0.00 & 1.2 \\
$\mathrm{NaCl}$ & 1.5 & $1.0 \times 10^{-8}$ & 2.2 \\
Crust & 1.53 & $1.1 \times 10^{-3}$ & 2.6 \\
\hline
\end{tabular}

EC, elemental carbon; OM, organic matter. 


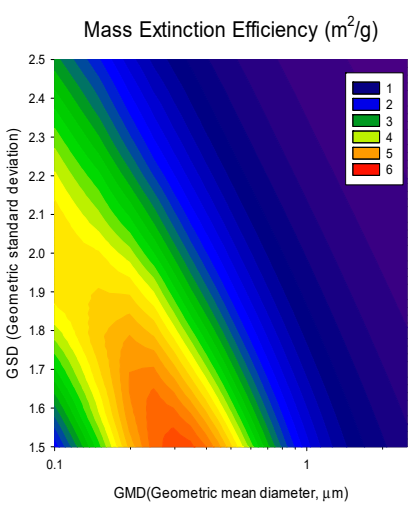

(a)

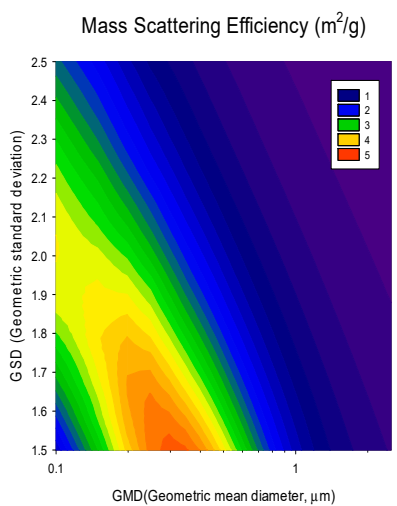

(b)

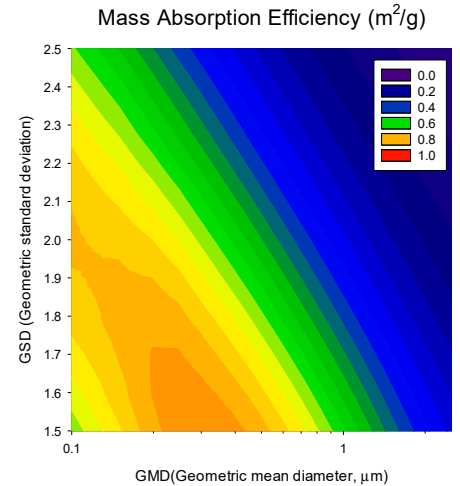

(c)

Figure 2. Sensitivity of (a) the mass extinction efficiency (MEE), (b) mass scattering efficiency (MSE), and (c) mass absorption efficiency (MAE) for internally mixed aerosol as a function of the geometric mean diameters $\left(\mathrm{d}_{\mathrm{g}}\right)$ in the range of $0.1-2.5 \mu \mathrm{m}$ and geometric standard deviations (GSD) in the range of 1.5-2.5.

A physical relationship between light extinction and atmospheric particle composition for externally mixed aerosol can be expressed by the following equations with respect to a given particle concentration, size distribution, refractive indices, and densities of each chemical species $[3,16,21]$ :

$$
\begin{gathered}
b_{\text {ext }}=\sum_{i} b_{\text {ext }, i} \\
b_{\text {ext }, i}=\frac{\pi d_{p}^{2}}{4} Q_{\text {ext }, i}\left(d_{p}, \lambda, m\right) n\left(d_{p}\right)
\end{gathered}
$$

where $b_{\text {ext, } i}$ is the extinction coefficient associated with the $i$ th species; $n\left(d_{p}\right)$ is the number distribution; $Q_{\text {ext, } i}\left(d_{p}, \lambda, m\right)$ is the extinction efficiency of a particle with a diameter, $d_{p}$ and a refractive index, $m$, at a specific wavelength, $\lambda$, for the $i$ th species. It should be noted that $b_{\text {ext }}$ can be expressed as a function of particle size.

For a given mass concentration, the overall extinction coefficient expressed in Equations (1) and (2) can be simplified as follows:

$$
b_{\text {ext }}=\sum_{i} b_{\text {ext, } i}=\sum_{i}\left[C_{i} \times M E E_{i}\right]
$$

where $M E E_{i}$ is the mass extinction efficiency in $\mathrm{m}^{2} \mathrm{~g}^{-1}$, and $C_{i}$ is the mass concentration of the $i$ th chemical species (in $\mu \mathrm{g} \mathrm{m}^{-3}$ ).

In this study, the resultant expression of $b_{\text {ext }}$ and $b_{a b s}$ for a dry aerosol can be expressed as follows:

$$
b_{\text {ext }}=\mathrm{MEE}_{[\text {Inorganic] }} \mathrm{C}_{[\text {Inorganic] }}+\mathrm{MEE}_{[\mathrm{OM}]} \mathrm{C}_{[\mathrm{OM}]}+\mathrm{MEE}_{[\mathrm{NaCl}]} \mathrm{C}_{[\mathrm{NaCl}]}+\mathrm{MEE}_{[\text {Crust] }} \mathrm{C}_{[\text {Crust }]}+\mathrm{MEE}_{[\mathrm{EC}]} \mathrm{C}_{[\mathrm{EC}]}
$$

where the MEE for each species is usually considered constant. However, for polydisperse aerosols, we must use size-dependent MEEs.

We obtained the MEE using Equation (5) from the $b_{\text {ext }}$ and mass concentration. The MEE is defined as the ratio between the aerosol extinction coefficient and the aerosol mass concentration in a unit volume of air $[7,22]$.

$$
M E E_{i}=\frac{b_{\text {ext }}}{C_{i}}
$$

We assumed that aerosols follow a log-normal size distribution, which is expressed as a function of $\mathrm{d}_{\mathrm{g}}$ and the GSD. 
Figure 3 shows the size-resolved MEEs for different chemical species and GSDs. A $d_{g}$ range of 0.1-2.5 $\mu \mathrm{m}$ was considered, and GSDs of 1.5, 2.1, and 2.5 were compared. As shown in Figure 3, the MEEs had different distributions that depended on the chemical species, which were characterized by different size distributions. According to Malm et al. [23], the MEE values for inorganic ion, $\mathrm{OM}, \mathrm{NaCl}$, crust, and EC are 3.0, 4.0, 1.7, 1.0, and $10.0 \mathrm{~m}^{2} \mathrm{~g}^{-1}$, which represent constants at specific conditions among the widely distributed MEEs.

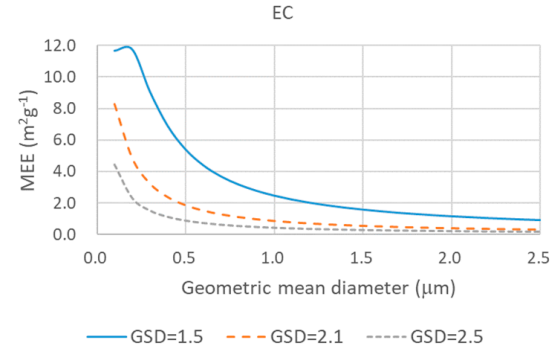

(a)

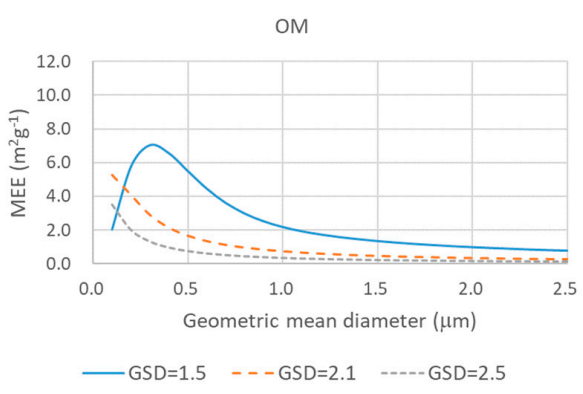

(c)

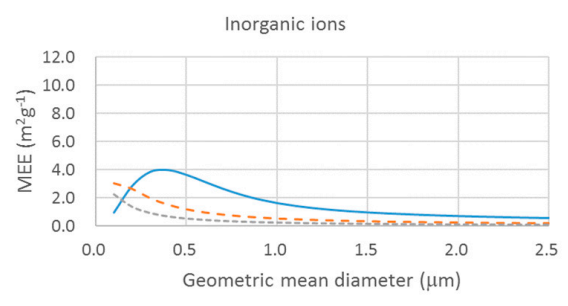

-GSD=1.5 - - - GSD=2.1 -----GSD=2.5

(b)

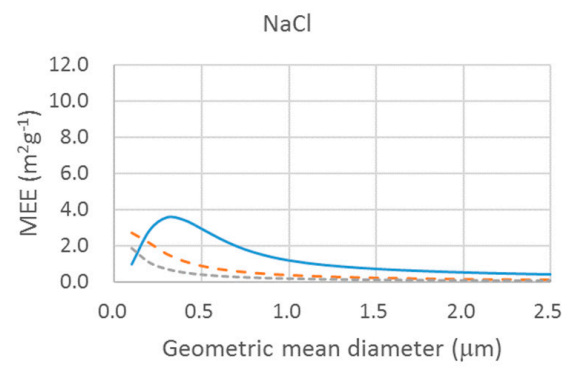

$-\mathrm{GSD}=1.5 \quad---\mathrm{GSD}=2.1 \quad----\mathrm{GSD}=2.5$

(d)

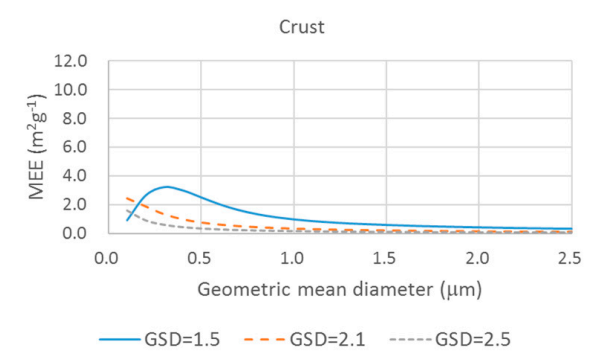

(e)

Figure 3. Composition-based mass extinction efficiency as a function of the geometric mean diameter for different geometric standard deviations for (a) elemental carbon (EC), (b) inorganic ions, (c) organic matter (OM), (d) $\mathrm{NaCl}$, and (e) Crust.

Figure 3 implies that the MEEs for polydisperse aerosols are influenced by many factors, including emissions, chemical signature, and meteorology. This suggests that we must pay careful attention when applying MEEs from previous studies that may have used different spatiotemporal conditions.

\subsection{Source-Based Aerosol Mass Extinction Efficiency for Polydisperse Aerosol Particles}

Based on the size-resolved $b_{\text {ext }}$ and source-resolved mass concentrations, we could estimate the size-resolved and the source-resolved MEEs. The total aerosol $b_{\text {ext }}$ can also be expressed as a combination of each source-based extinction coefficient. Here, we obtained the source-based MEEs from the source-based mass concentration in the SMP receptor model, and the total aerosol extinction coefficient from Mie theory. We estimated MEEs by applying the MLR method [24]: 


$$
b_{\text {ext }}=\sum_{s} b_{\text {ext }, s}=\sum_{s}\left[C_{s=\text { source }} \times M E E_{S}\right]
$$

where $M E E_{s}$ is the mass extinction efficiency of sth source (in $\mathrm{m}^{2} \mathrm{~g}^{-1}$ ), and $C_{s}$ is the mass concentration of the sth source from the SMP results (in $\mu \mathrm{g} \mathrm{m}^{-3}$ ).

Multilinear regression is a useful tool for estimating aerosol optical parameters, such as MEE [10-12]. For example, a previous study [11] investigated aerosol optical properties, mass concentrations, and chemical compositions over a one-year period and obtained the total scattering coefficient using MLR analysis. The authors calculated the total scattering coefficient as the independent variable, and the sulfate ion, nitrate ion, mineral matter, organic and elemental carbon, and residual fraction mass concentrations as the dependent variables.

Using Equation (6), we obtained the total aerosol $b_{\text {ext }}$ in Equation (3) based on the mass concentration of the sources. As explained, the SMP model can provide the mass concentration of each source. Subsequently, the MLR method can provide the MEE of each source. All the derived MEEs from MLR were within the 95\% confidence interval and significance at the 0.05 level. It should be also noted that all $b_{\text {ext }}$ and MEE values are size-dependent [25]. We carefully estimated the MEEs for polydisperse aerosols as a function of $d_{g}$ and GSD. Among the nine sources based on the SMP results [14], contributions from WB were very low, except for four days when the WB contribution was high. For this reason, WB was not considered, and we excluded the optical contribution from WB when estimating $b_{\text {ext }}$ and MEEs.

\section{Results and Discussion}

Figure 4 shows the size-resolved MEE for each different source based on the results of Equation (6). A $d_{g}$ of $0.1-2.5 \mu \mathrm{m}$ and GSDs of 1.5, 2.1, and 2.5 were considered. For a GSD of 1.5, maximum MEEs were $4.471 \mathrm{~m}^{2} \mathrm{~g}^{-1}$ for TS ( $\mathrm{d}_{\mathrm{g}}$ of $\left.0.3 \mu \mathrm{m}\right), 3.802 \mathrm{~m}^{2} \mathrm{~g}^{-1}$ for LS $\left(\mathrm{d}_{\mathrm{g}}\right.$ of $\left.0.4 \mu \mathrm{m}\right), 5.064 \mathrm{~m}^{2} \mathrm{~g}^{-1}$ for LN ( $\mathrm{d}_{\mathrm{g}}$ of $\left.0.3 \mu \mathrm{m}\right), 3.418 \mathrm{~m}^{2} \mathrm{~g}^{-1}$ for $\mathrm{G}\left(\mathrm{d}_{\mathrm{g}}\right.$ of $\left.0.3 \mu \mathrm{m}\right), 11.004 \mathrm{~m}^{2} \mathrm{~g}^{-1}$ for $\mathrm{D}\left(\mathrm{d}_{\mathrm{g}}\right.$ of $\left.0.2 \mu \mathrm{m}\right), 10.229 \mathrm{~m}^{2} \mathrm{~g}^{-1}$ for TBB $\left(\mathrm{d}_{\mathrm{g}}\right.$ of $\left.0.3 \mu \mathrm{m}\right), 6.335 \mathrm{~m}^{2} \mathrm{~g}^{-1}$ for LBB ( $\mathrm{d}_{\mathrm{g}}$ of $\left.0.3 \mu \mathrm{m}\right)$, and $1.655 \mathrm{~m}^{2} \mathrm{~g}^{-1}$ for FSD $\left(\mathrm{d}_{\mathrm{g}}\right.$ of $\left.0.3 \mu \mathrm{m}\right)$.

As the properties (MEE, MAE, and MSE) are size-dependent for each chemical compound and source, there are many ranges depending on GSD and $d_{g}$. Table 2 shows the ranges of MEE, MAE, and MSE for each source for GDS of 1.5-2.5 and $d_{g}$ of 0.1-2.5 $\mu \mathrm{m}$. The values extended over a wide range. Taking TS as an example, the maximum MEE, MAE, and MSE ranged from 0.098 to $4.471,0.000$ to 0.112 , and 0.061 to $4.471 \mathrm{~m}^{2} \mathrm{~g}^{-1}$, respectively.

Table 2. Ranges of MEE, MAE, and MSE for each source in the GSD range of 1.5-2.5 and the $\mathrm{d}_{\mathrm{g}}$ range of $0.1-2.5 \mu \mathrm{m}$.

\begin{tabular}{ccccc}
\hline Source & Range & MEE & MAE & MSE \\
\hline \multirow{2}{*}{ TS } & $\min$ & 0.098 & 0.000 & 0.061 \\
& $\max$ & 4.471 & 0.112 & 4.471 \\
LS & $\min$ & 0.089 & 0.036 & 0.053 \\
& $\max$ & 3.802 & 0.397 & 3.409 \\
LN & $\min$ & 0.110 & 0.047 & 0.063 \\
& $\max$ & 5.064 & 0.345 & 4.792 \\
G & $\min$ & 0.062 & 0.034 & 0.028 \\
& $\max$ & 3.418 & 0.750 & 2.693 \\
D & $\min$ & 0.185 & 0.099 & 0.086 \\
& $\max$ & 11.004 & 4.604 & 6.438 \\
TBB & $\min$ & 0.191 & 0.084 & 0.107 \\
& $\max$ & 10.229 & 1.143 & 9.126 \\
LBB & $\min$ & 0.125 & 0.000 & 0.069 \\
& $\max$ & 6.335 & 0.246 & 6.335 \\
FSD & $\min$ & 0.031 & 0.019 & 0.012 \\
& $\max$ & 1.655 & 0.458 & 1.197 \\
\hline
\end{tabular}

TS, transported secondary sources; LS, local secondary sulfates; LN, local secondary nitrates; G, gasoline; D, diesel; TBB, transported biomass burning; LBB, local biomass burning; FSD, fugitive soil dust; MEE, mass extinction efficiency; MAE, mass absorption efficiency; MSE, mass scattering efficiency. 
TS

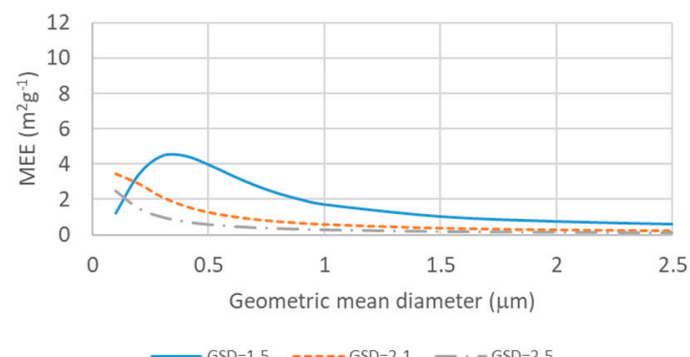

(a)

LN

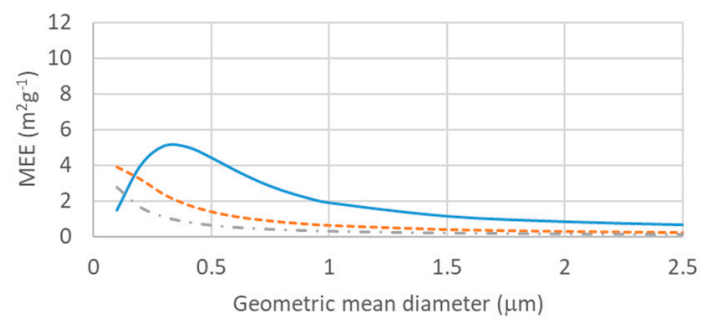

(c)

D

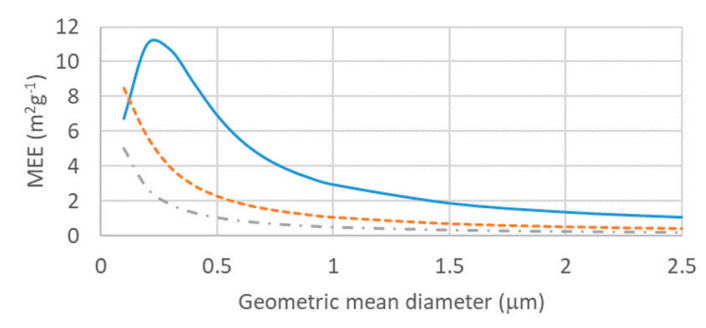

$\longrightarrow$ GSD $=1.5 \quad----$ GSD $=2.1 \quad \cdots \quad-G S D=2.5$

(e)

LBB

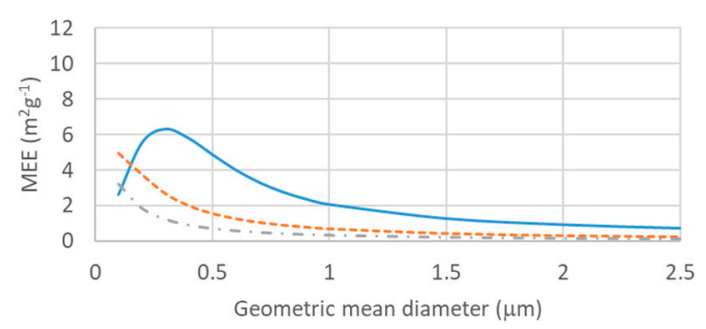

$-G S D=1.5-----G S D=2.1-\cdot-G S D=2.5$

(g)
LS

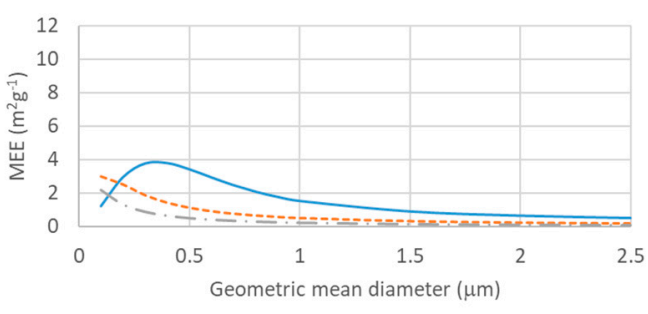

$\longrightarrow G S D=1.5 \quad-----G S D=2.1 \quad-\cdot-G S D=2.5$

(b)

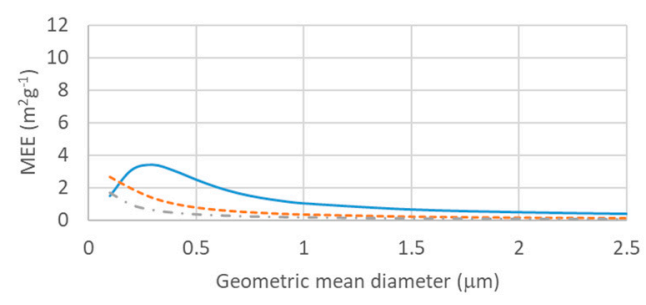

(d)

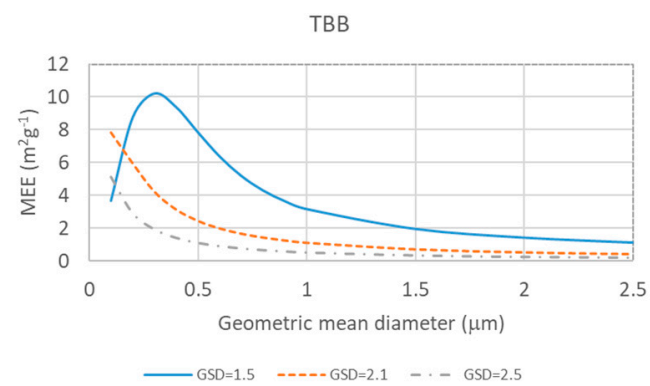

(f)

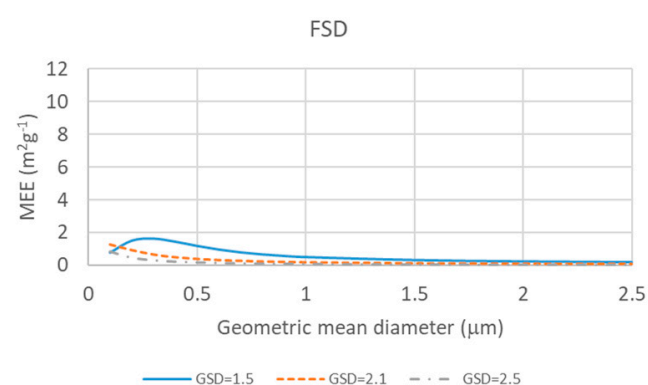

(h)

Figure 4. Source-based mass extinction efficiency as a function of the geometric mean diameter for different geometric standard deviations for (a) transported secondary sources (TS), (b) local secondary sulfates (LS), (c) local secondary nitrates (LN), (d) gasoline (G), (e) diesel (D), (f) transported biomass burning (TBB), (g) local biomass burning (LBB), and (h) fugitive soil dust (FSD).

As shown in Figure 4, the MEEs peaked at a $\mathrm{d}_{\mathrm{g}}$ of $\sim 0.3 \mu \mathrm{m}$ for a GSD of 1.5 for all sources and showed a declining trend as $d_{g}$ increased. The $d_{g}$ at which MEEs had peak values decreased as GSD increased. However, detailed MEE values differed depending on the sources. Figure 4 shows that $\mathrm{D}$ and TBB sources had relatively higher MEE values compared with the other sources. They had 
maximum values higher than $10 \mathrm{~m}^{2} \mathrm{~g}^{-1}$ in submicron sizes for a GSD value of 1.5 . Meanwhile, the FSD and the G sources were characterized by relatively lower MEEs with maximum values of less than 2 and $3 \mathrm{~m}^{2} \mathrm{~g}^{-1}$, respectively, for a GSD of 1.5. Thus, assuming size-dependent MEEs as constant variables may result in significant errors in estimating aerosol optical properties.

Another important parameter in estimating aerosol optical properties is the aerosol light-absorbing property. This light absorption property is mainly determined by EC. As shown in Table 1, the imaginary refractive index was 0.44 , which means that EC was the main light-absorbing compound. In this study, we assumed OM to be a non-absorbing compound. However, some OM (e.g., HULIS) is known to have weakly to moderate light-absorbing ability depending on its characteristics $[8,9]$. In order to identify the effects of the source-resolved MEEs on HULIS light-absorbing property, HULIS imaginary refractive index was tested. Figure 5 compares the size-resolved MEE for each source with the various HULIS imaginary refractive indices. The HULIS imaginary refractive indices of 0.006 and 0.1 with a GSD value of 1.5 were compared. As shown in Figure 5, the TS, LS, and FSD sources had an insignificant impact on the variation of HULIS imaginary refractive index. However, biomass burning sources (D, TBB, and LBB) showed discrepancies at a $\mathrm{d}_{\mathrm{g}}$ value of $1.5 \mu \mathrm{m}$, which indicates that the HULIS imaginary refractive index had a stronger influence on these sources than on other sources.

Figure 6 shows the trends of the source-resolved total extinction coefficient $\left(b_{\text {ext }}\right)$ and their contributions. The $\mathrm{d}_{\mathrm{g}}$ values of 0.1 and $0.5 \mu \mathrm{m}$ were compared, with a GSD of 1.5 during the sampling period. The source-resolved mass concentration is also displayed in Figure 6 [14]. In general, the trends of the source-based optical property were similar to those of the source-based mass concentrations [14] (see also contribution of mass in Supplementary Figure S3). However, the specific contributions to $b_{\text {ext }}$ and mass were different according to the sources. Total $b_{\text {ext }}$ values were generally high during winter and spring and low during summer. In the source-based analysis, the $b_{\text {ext }}$ associated with some sources such as $G$ and LBB did not show significant seasonal variation. The contributions of $G$ and LBB were relatively consistent regardless of the season. However, the contributions of transported sources (TS and TBB) showed relatively distinct seasonal characteristics: they were high during winter and low during summer. For LN, the contribution increased during winter and spring but remained low in summer. The contribution of LS was great in summer and low in winter.

Figure 6 also shows that $b_{\text {ext }}$ increased as $\mathrm{d}_{\mathrm{g}}$ increased from 0.1 to $0.5 \mu \mathrm{m}$. This was due to the MEE with a GSD of 1.5, which increased as $d_{g}$ increased from 0.1 to $0.5 \mu \mathrm{m}$ (except for EC), as shown in Figure 3. Although there were differences in the $b_{\text {ext }}$ values, the contributions of each source were similar.

Table 3 shows the source-based extinction coefficients across the whole sampling period with different geometric mean diameters $(\mathrm{GSD}=1.5)$. The $b_{\text {ext }}$ will have different values for different GSDs. As Table 3 clearly shows, size distributions can influence source-based $b_{\text {ext }}$ values.

Table 3. Source-based extinction coefficients $\left(b_{\text {ext }}, \mathrm{Mm}^{-1}\right)$ for different geometric mean diameters (geometric standard deviation $=1.5$ ).

\begin{tabular}{ccccccccc}
\hline $\mathbf{d}_{\mathbf{g}}(\boldsymbol{\mu m})$ & TS & LS & LN & G & D & TBB & LBB & FSD \\
\hline 0.1 & 9.3 & 10.0 & 12.7 & 4.6 & 16.2 & 11.1 & 5.2 & 2.4 \\
0.2 & 26.6 & 24.0 & 34.5 & 9.7 & 26.5 & 26.4 & 11.0 & 4.8 \\
0.3 & 34.7 & 30.7 & 44.1 & 10.7 & 25.7 & 30.8 & 12.6 & 5.2 \\
0.4 & 34.7 & 30.8 & 43.5 & 9.5 & 21.2 & 28.3 & 11.6 & 4.6 \\
0.5 & 30.9 & 27.9 & 38.4 & 7.8 & 16.7 & 23.7 & 9.8 & 3.8 \\
0.6 & 26.1 & 23.9 & 32.4 & 6.3 & 13.3 & 19.2 & 8.0 & 3.1 \\
0.7 & 21.7 & 20.2 & 26.9 & 5.1 & 10.9 & 15.6 & 6.6 & 2.5 \\
0.8 & 18.1 & 17.0 & 22.5 & 4.3 & 9.3 & 13.0 & 5.5 & 2.1 \\
0.9 & 15.3 & 14.5 & 19.0 & 3.6 & 8.0 & 11.0 & 4.7 & 1.8 \\
1.0 & 13.2 & 12.5 & 16.4 & 3.2 & 7.1 & 9.6 & 4.1 & 1.6
\end{tabular}

TS, transported secondary sources; LS, local secondary sulfates; LN, local secondary nitrates; G, gasoline; D, diesel; TBB, transported biomass burning; LBB, local biomass burning; FSD, fugitive soil dust. 
TS

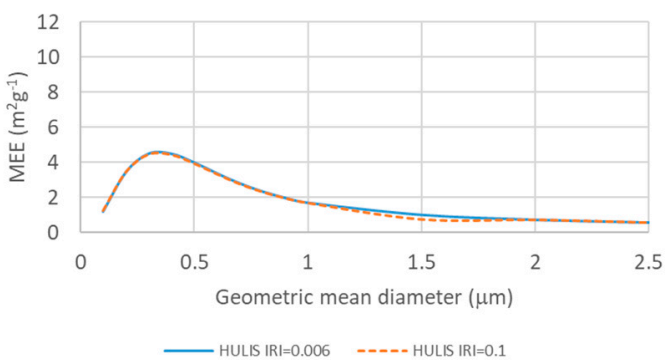

(a)

LN

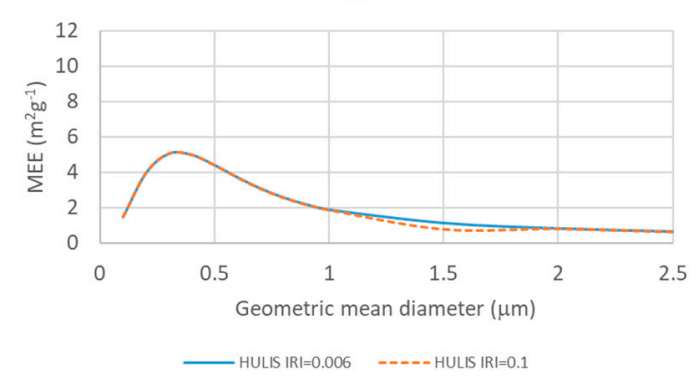

(c)

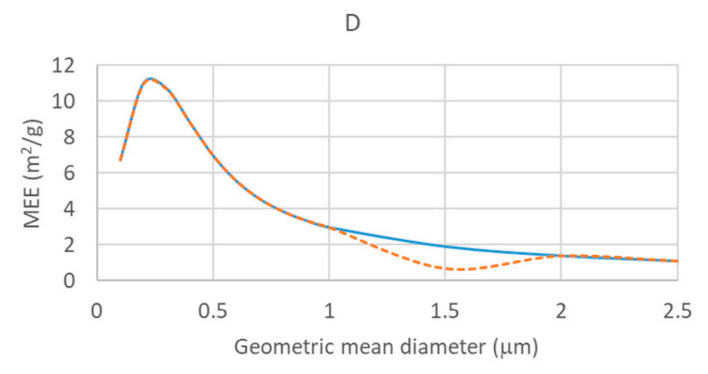

— HULIS $|R|=0.006 \quad-----$ HULIS $|R|=0.1$

(e)

LBB

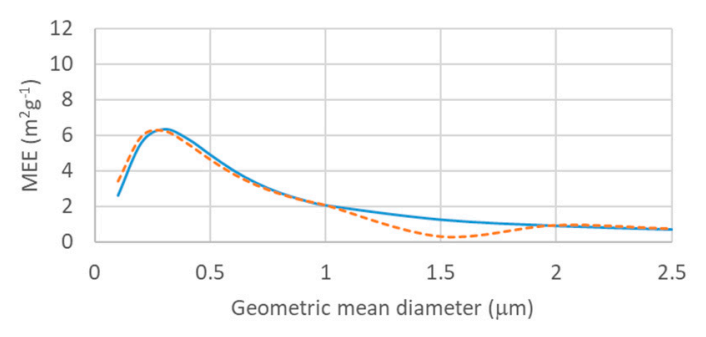

(g)
LS

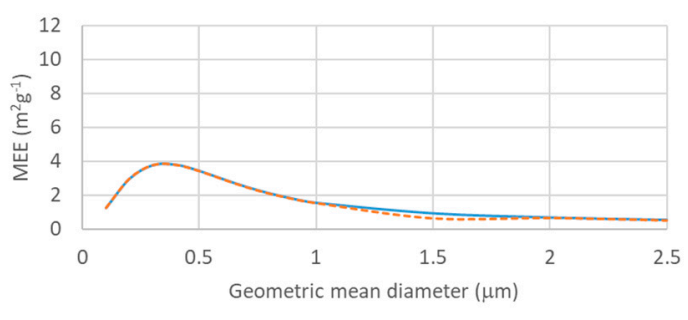

— HULIS $|R|=0.006 \quad----$ HULIS $|R|=0.1$

(b)

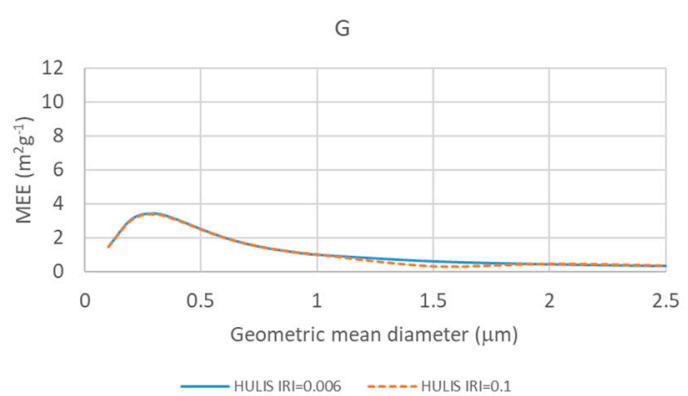

(d)

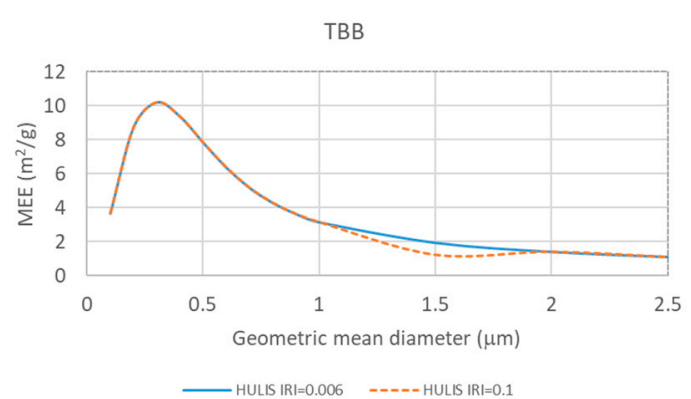

(f)

FSD

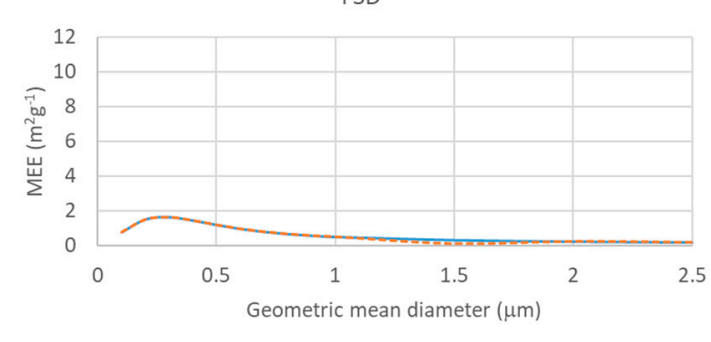

(h)

Figure 5. Composition-based mass extinction efficiency as a function of the geometric mean diameter for different humic-like carbon substance (HULIS) imaginary refractive indices (GSD = 1.5) for (a) TS, (b) LS, (c) LN, (d) G, (e) D, (f) TBB, (g) LBB, and (h) FSD.

Figure 7 compares the source-based mass contributions with the source-based $b_{\text {ext }}$ contributions for different $d_{g}$ values. The average values were based on the whole sampling period. In this study, several size distributions with geometric mean diameters of $0.1,0.3,0.5$, and $1.0 \mu \mathrm{m}$ for a GSD of 1.5 were considered. Supplementary Figure S3 shows detailed mass concentrations and their contributions based on chemical compounds and sources. 


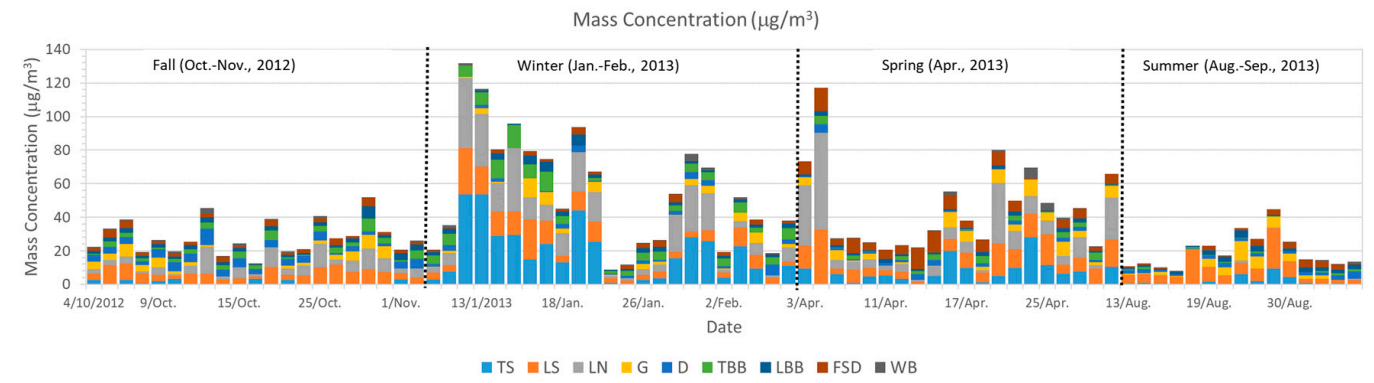

(a)

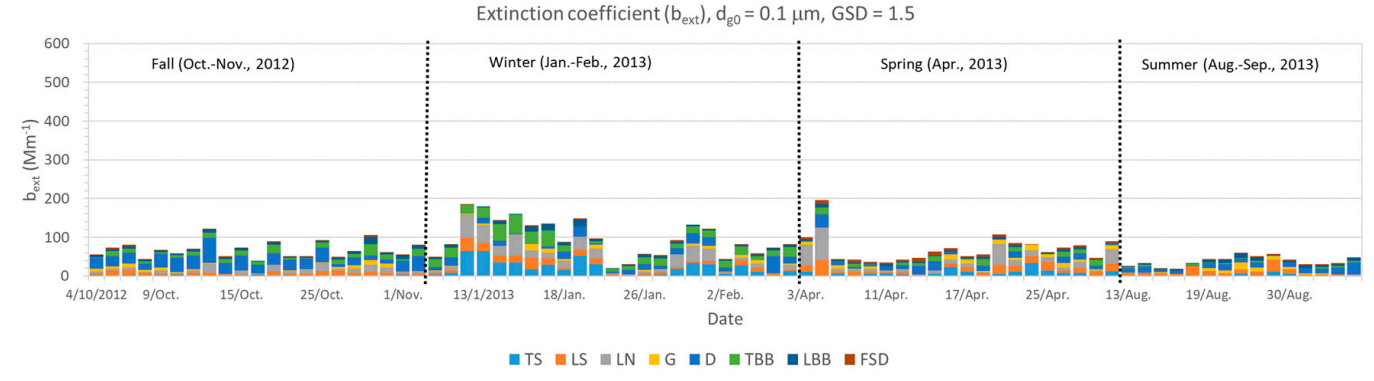

(b)

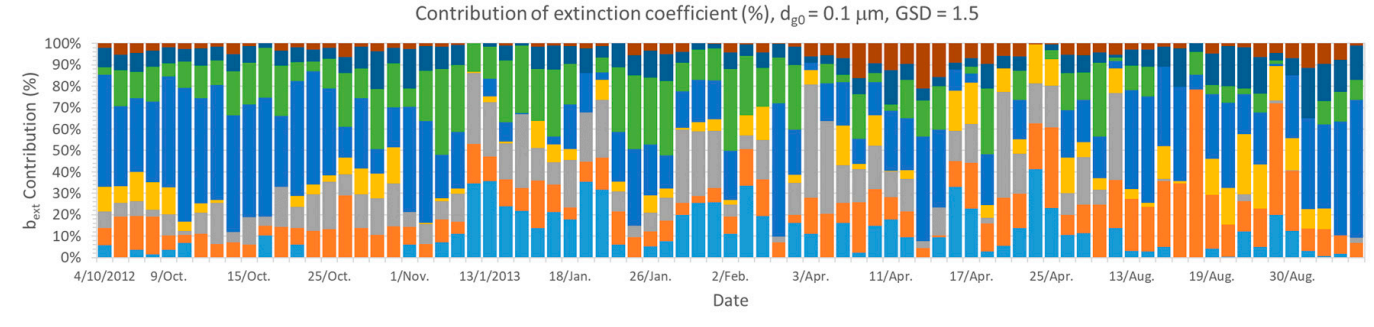

(c)

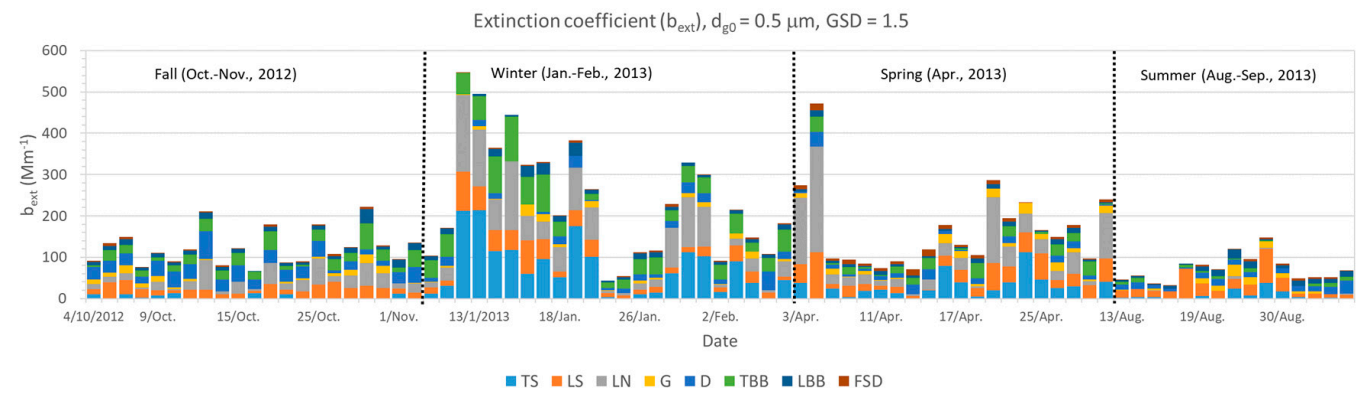

(d)

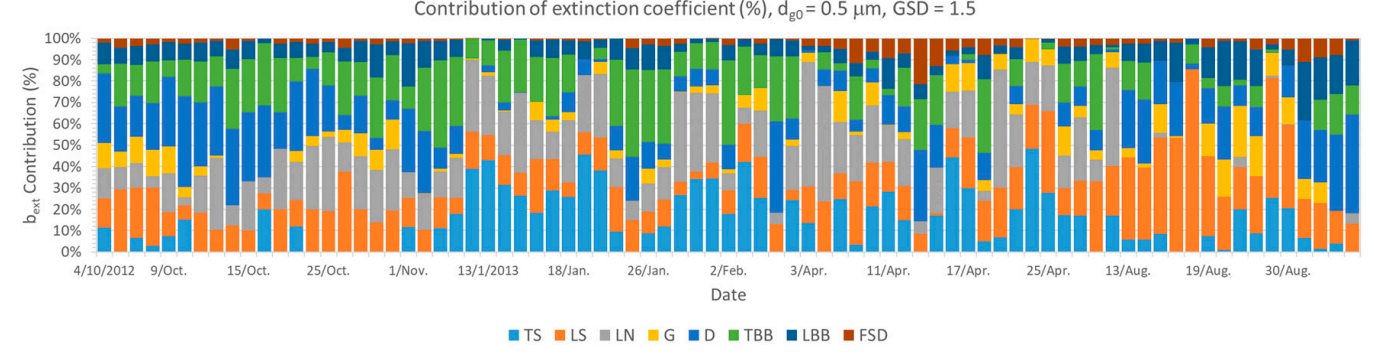

(e)

Figure 6. (a) Source-based mass concentrations, (b) source-based extinction coefficients $\left(\mathrm{d}_{\mathrm{g}}=0.1 \mu \mathrm{m}\right.$, $\mathrm{GSD}=1.5)$, (c) contribution of the source-based extinction coefficients $\left(\mathrm{d}_{\mathrm{g}}=0.1 \mu \mathrm{m}, \mathrm{GSD}=1.5\right)$, (d) source-based extinction coefficients $\left(\mathrm{d}_{\mathrm{g}}=0.5 \mu \mathrm{m}, \mathrm{GSD}=1.5\right)$, and (e) contribution of source-based extinction coefficients $\left(\mathrm{d}_{\mathrm{g}}=0.5 \mu \mathrm{m}, \mathrm{GSD}=1.5\right)$ during sampling periods. 


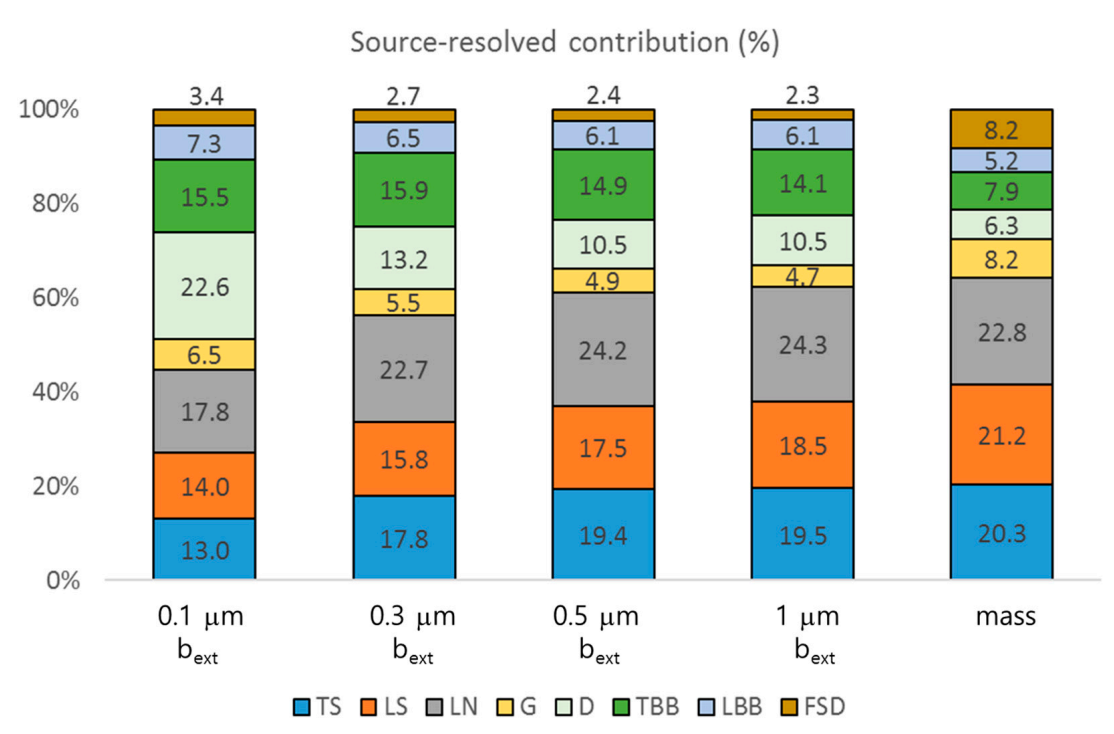

Figure 7. Comparisons of the average source-based mass contribution with the source-based $b_{\text {ext }}$ contributions $(\mathrm{GSD}=1.5)$.

The mass contributions of each source are shown in Figure 7. Figure 7 shows contributions of $20.3 \%, 21.2 \%, 22.8 \%, 8.2 \%, 6.3 \%, 7.9 \%, 5.2 \%$, and $8.2 \%$ by TS, LS, LN, G, D, TBB, LBB, and FSD, respectively. The contribution of $b_{\text {ext }}$ depended on the size distribution. For example, for $d_{g}$ of $0.1 \mu \mathrm{m}$ and a GSD of 1.5 , the contributions made by D, TBB, and LBB to mass and to $b_{\text {ext }}$ increased from $6.3 \%$, $7.9 \%$, and $5.2 \%$ for mass to $22.6 \%, 15.5 \%$, and $7.3 \%$ for $b_{\text {ext }}$, respectively. Meanwhile, the contributions of TS, LS, LN, G, and FSD decreased from 20.3\% (TS), 21.2\% (LS), 22.8\% (LN), 8.2\% (G), 8.2\% (FSD) for mass to $13 \%$ (TS), $14 \%$ (LS), $17.8 \%$ (LN), $6.5 \%$ (G), and 3.4\% (FSD) for $b_{\text {ext }}$, respectively.

Theoretically, the MEE for each source is the extinction coefficient to mass ratio in $\mathrm{m}^{2} / \mathrm{g}$, which is shown in Figure 4. This means that sources with large MEE values (D, TBB) had higher contributions to the extinction coefficient compared with other sources.

Under the condition of a GSD of 1.5 and $\mathrm{d}_{\mathrm{g}}$ of $0.1 \mu \mathrm{m}$, the ratio of total $b_{\text {ext }}$ to PM2.5 mass concentration was $1.7 \mathrm{~m}^{2} / \mathrm{g}$. Sources with MEE higher than $1.7 \mathrm{~m}^{2} / \mathrm{g}$ will make larger contributions to $b_{\text {ext }}$ than to mass, and sources with MEE lower than $1.7 \mathrm{~m}^{2} / \mathrm{g}$ will make smaller contributions to $b_{\text {ext }}$ than to mass. As shown in Figure 7, the contributions of $b_{\text {ext }}$ for TS (MEE $=1.2$ for a GSD of 1.5 and $\mathrm{d}_{\mathrm{g}}$ of $\left.0.1 \mu \mathrm{m}\right)$, $\mathrm{LS}(\mathrm{MEE}=1.234), \mathrm{LN}(\mathrm{MEE}=1.463), \mathrm{G}(\mathrm{MEE}=1.478)$, and FSD (MEE = 0.775) to total $b_{\text {ext }}$ became smaller as compared to the mass contribution. In contrast, the contributions of $b_{\text {ext }}$ for $\mathrm{D}(\mathrm{MEE}=6.735), \mathrm{TBB}(\mathrm{MEE}=3.679)$, and LBB $(\mathrm{MEE}=2.634)$ to total $b_{\text {ext }}$ became larger as compared to the contribution based on chemical compound mass concentration. It should also be noted that sources containing EC increased the MEE, and this made the contribution of sources containing EC to $b_{\text {ext }}$ increase compared with the contribution to mass. Figure 7 shows how the size distribution and refractive index influenced the source-based $b_{\text {ext }}$ contribution.

As discussed, the optical properties depend on chemical species mass concentration. It was important to validate the reliability of the obtained $b_{\text {ext }}$. In this study, we compared our $b_{\text {ext }}$ with AOD (Aerosol Optical Depth) from the Aerosol Robotic Network (AERONET) network. The AOD is the integration of $b_{\text {ext }}$ over the height $(\mathrm{z})$ of the atmospheric column between sensor and sun [26]:

$$
\mathrm{AOD}=\int_{0}^{z} b_{\text {ext }} d z
$$

Figure 8 shows a comparison of the daily averaged AOD in Seoul from the AERONET Seoul-SNU station ( $37.458 \mathrm{~N}, 126.951 \mathrm{E})$ with the obtained extinction coefficient $\left(b_{\text {ext }}\right)$ based on daily mass concentration data of species [27]. The comparison yielded $R^{2}$ of 0.60 to 0.68 for the $d_{g}$ range of 0.1-2.5 $\mu \mathrm{m}$ at a GSD of 1.5. A more direct measurement comparison, such as of in situ aerosol scattering 
coefficient values from nephelometer scattering, was not possible because of data unavailability. However, the comparison between AOD from AERONET and our calculated $b_{\text {ext }}$ showed a comparable correlation and regression.

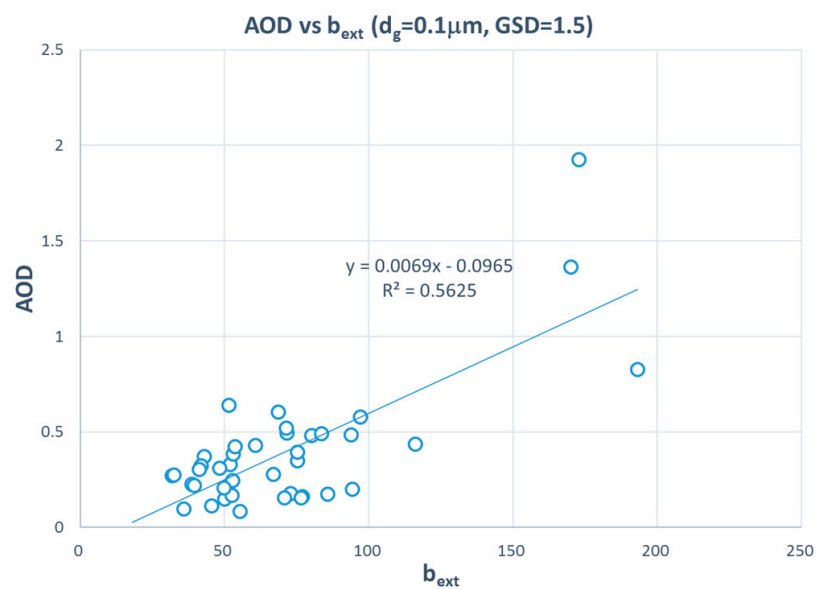

(a)

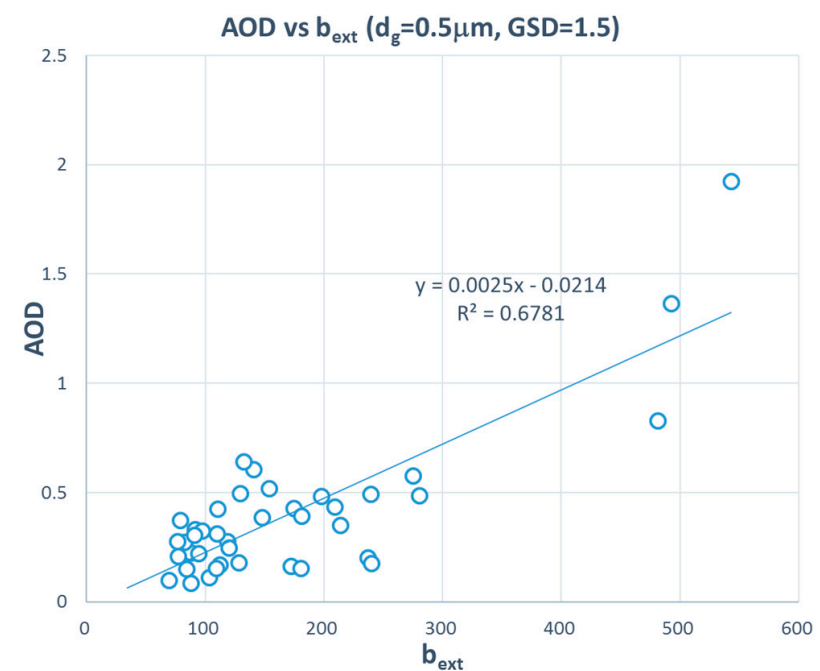

(b)

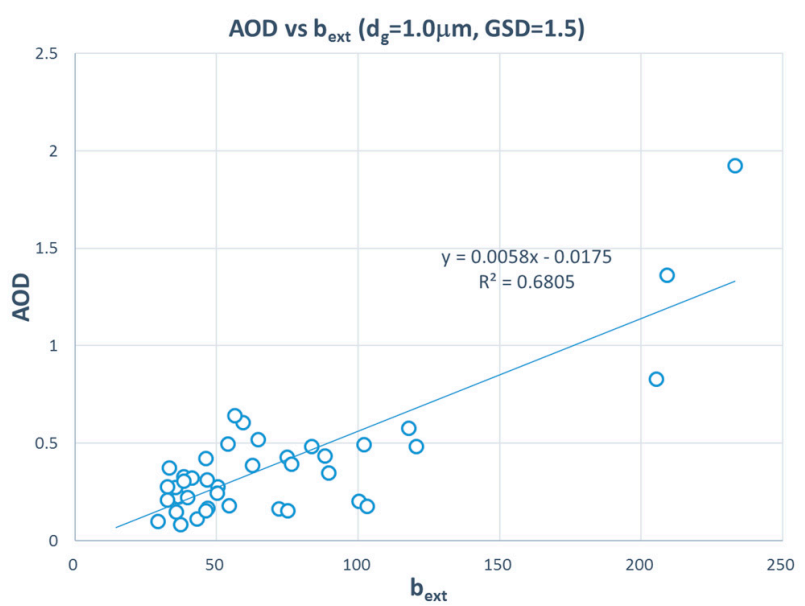

(c)

Figure 8. Comparisons of our determined $b_{\text {ext }}$ with AOD (Aerosol Optical Depth) from Aerosol Robotic Network (AERONET) (Seoul-SNU station, $37.458 \mathrm{~N}, 126.951 \mathrm{E}$ ) during the sampling period for a GSD $=1.5$ and for $(\mathbf{a}) \mathrm{dg}=0.1 \mu \mathrm{m},(\mathbf{b}) \mathrm{dg}=0.5 \mu \mathrm{m}$, and (c) $\mathrm{dg}=1.0 \mu \mathrm{m}$. 


\section{Conclusions}

In this study, the source-based MEE for polydisperse aerosols was estimated according to the results of the source apportionment-based chemical-species-resolved mass contribution. The aerosol extinction coefficient was calculated on the basis of the chemical composition mass concentrations of EC, WSOC (HULIS-C and the rest), WISOC, and inorganic ions from a one-year-long PM2.5 measurement sequence in Seoul, Korea. The aerosol extinction coefficients for polydisperse aerosols were calculated, and the source-based optical properties were characterized using a multivariate receptor model [14].

The results show that the source apportionment-based aerosol optical properties depend on the aerosol size distribution as well as on their physico-chemical characteristics. Comparisons between the contributions to mass and those to $b_{\text {ext }}$ showed that carbon-containing sources made a relatively larger contribution to the $b_{\text {ext }}$ than to mass.

This study also shows that the HULIS imaginary refractive index influences the MEE for biomass burning sources (TBB and LBB), especially for large particles ( $\mathrm{d}_{\mathrm{g}}$ of $1.5 \mu \mathrm{m}$, a GSD of $1.5 \mu \mathrm{m}$ ). For $\mathrm{D}$, $\mathrm{TBB}$, and $\mathrm{LBB}$, the contributions to $b_{\text {ext }}$ became larger as compared to the source contributions to mass concentration, which indicates that the contribution to $b_{\text {ext }}$ by these sources is possibly more important than that those to mass.

The size distributions of different species could be different. However, a single cumulative measurement (PM2.5) cannot provide size-resolved information for chemical composition. A more detailed size distribution with chemical species data is required in order to obtain more accurate results.

Supplementary Materials: The following are available online at http:/ / www.mdpi.com/2076-3417/9/7/1443/ s1.

Author Contributions: C.H.J. and J.Y.L. designed the research and wrote the manuscript. J.U. and S.S.L. analyzed the model results. Y.J.Y. and Y.P.K. performed the data analysis and interpreted the results.

Funding: This research was supported by the National Strategic Project-Fine particle of the National Research Foundation of Korea (NRF) funded by the Ministry of Science and ICT (MSIT), the Ministry of Environment (ME), and the Ministry of Health and Welfare (MOHW; NRF-2017M3D8A1092022). Support also came from the KOPRI program (PN19081), which is funded by the National Research Foundation of Korea Grant (NRF-2016M1A5A1901786).

Conflicts of Interest: The authors declare no conflict of interest

\section{References}

1. Pilinis, C.; Pandis, S.N.; Seinfeld, J.H. Sensitivity of direct climate forcing by atmospheric aerosols to aerosol size and composition. J. Geophys. Res. 1995, 100, 18739-18754. [CrossRef]

2. Cheng, Z.; Ma, X.; He, Y.; Jiang, J.; Wang, X.; Wang, Y.; Sheng, L.; Hu, J.; Yan, N. Mass extinction efficiency and extinction hygroscopicity of ambient PM2.5 in urban China. Environ. Res. 2017, 156, 239-246. [CrossRef] [PubMed]

3. Jung, C.H.; Um, J.; Bae, S.Y.; Yoon, Y.J.; Lee, S.S.; Kim, Y.P. Analytic expression for the aerosol mass efficiencies for polydispersed accumulation mode. Aerosol Air Qual. Res. 2018, 18, 1503-1514. [CrossRef]

4. Horvath, H. Atmospheric light absorption-A review. Atmos. Environ. 1993, 27, 293-317. [CrossRef]

5. Watson, J.G. Overview of receptor model principles. J. Air Pollut. Contr. Assoc. 1984, 34, 620-623. [CrossRef]

6. Lowenthal, D.H.; Watson, J.G.; Saxena, P. Contributions to light extinction during project MOHAVE. Atmos. Environ. 2000, 34, 2351-2359. [CrossRef]

7. Malm, W.C.; Day, D.; Kreidenweis, S. Light scattering characteristics of aerosols as a function of relative humidity: Part I-A comparison of measured scattering and aerosol concentrations using the theoretical models. J. Air Waste Manag. Assoc. 2000, 50, 686-700. [CrossRef]

8. Jung, C.H.; Shin, H.J.; Lee, J.Y.; Kim, Y.P. Sensitivity and contribution of organic aerosols to aerosol optical properties based on their refractive index and hygroscopicity. Atmosphere 2016, 7, 65. [CrossRef]

9. Lee, J.Y.; Jung, C.H.; Kim, Y.P. Estimation of Optical Properties for HULIS Aerosols at Anmyeon Island, Korea. Atmosphere 2017, 8, 120. [CrossRef] 
10. Chan, Y.C.; Simpson, R.W.; Mctainsh, G.H.; Vowles, P.D.; Cohen, D.D.; Bailey, G.M. Source apportionment of visibility degradation problems in Brisbane (Australia) using the multiple linear regression techniques. Atmos. Environ. 1999, 33, 3237-3250. [CrossRef]

11. Titos, G.; Foyo-Moreno, I.; Lyamani, H.; Querol, X.; Alastuey, A.; Alados-Arboledas, L. Optical properties and chemical composition of aerosol particles at an urban location: An estimation of the aerosol mass scattering and absorption efficiencies. J. Geophys. Res. 2012, 117, D04206. [CrossRef]

12. Tao, J.; Zhang, L.; Cao, J.; Hsu, S.C.; Xia, X.; Zhang, Z.; Lin, Z.; Cheng, T.; Zhang, R. Characterization and source apportionment of aerosol light extinction in Chengdu, southwest China. Atmos. Environ. 2014, 95, 552-562. [CrossRef]

13. Paatero, P.; Tapper, U. Positive matrix factorization: A non-negative factor model with optimal utilization of error estimates of data values. Environmetrics 1994, 5, 111-126. [CrossRef]

14. Kim, B.M.; Seo, J.; Kim, J.Y.; Lee, J.Y.; Kim, Y.P. Transported vs. local contributions from secondary and biomass burning sources to PM2.5. Atmos. Environ. 2016, 144, 24-36. [CrossRef]

15. Bohren, C.F.; Huffman, D.R. Absorption and Scattering of Light by Small Particles; John Wiley \& Sons: New York, NY, USA, 1983.

16. Sloane, C.S. Optical properties of aerosols of mixed composition. Atmos. Environ. 1984, 18, 871-878. [CrossRef]

17. Arola, A.; Schuster, G.; Myhre, G.; Kazadzis, S.; Dey, S.; Tripathi, S.N. Inferring absorbing organic carbon content from AERONET data. Atmos. Chem. Phys. 2011, 11, 215-225. [CrossRef]

18. Hess, M.; Koepke, P.; Schult, I. Optical properties of aerosols and clouds: The software package OPAC. Bull. Am. Meteor. Soc. 1998, 79, 831-844. [CrossRef]

19. Dillner, A.M.; Stein, C.; Larson, S.M.; Hitzenberger, R. Measuring the Mass Extinction Efficiency of Elemental Carbon in Rural Aerosol. Aerosol Sci. Technol. 2001, 35, 1009-1021. [CrossRef]

20. Lesins, G.; Chylek, P.; Lohmann, U. A study of internal and external mixing scenarios and its effect on aerosol optical properties and direct radiative forcing. J. Geophys. Res. 2002, 107, 4094. [CrossRef]

21. Sloane, C.S.; Watson, J.; Chow, J.; Pritchett, L.; Richards, L.W. Size-segregated fine particle measurements by chemical species and their impact on visibility impairment in Denver. Atmos. Environ. 1991, 25, 1013-1024. [CrossRef]

22. Hand, J.L.; Malm, W.C. Review of aerosol mass scattering efficiencies from ground-based measurements since 1990. J. Geophys. Res. 2007, 112, D16203. [CrossRef]

23. Malm, W.C.; Sisler, J.F.; Huffman, D.; Eldred, R.A.; Cahill, T.A. Spatial and seasonal trends in particle concentration and optical extinction in the United States. J. Geophys. Res. 1994, 99, 1347-1370. [CrossRef]

24. Fox, J. Applied Regression Analysis, Linear Models and Related Methods; Sage Publication, Inc.: Thousand Oaks, CA, USA, 1997.

25. Jung, C.H.; Kim, Y.P. Particle extinction coefficient for polydispersed aerosol using a harmonic mean type general approximated solution. Aerosol Sci. Technol. 2007, 41, 994-1001. [CrossRef]

26. Seinfeld, J.H.; Pandis, S.N. Atmospheric Chemistry and Physics; Wiley: New York, NY, USA, 1998.

27. Holben, B.N.; Tanré, D.; Smirnov, A.; Eck, T.; Slutsker, I.; Abuhassan, N.; Newcomb, W.; Schafer, J.; Chatenet, B.; Lavenu, F.; et al. An emerging ground-based aerosol climatology: Aerosol optical depth from AERONET. J. Geophys. Res. 2001, 106, 12067-12097. [CrossRef]

(C) 2019 by the authors. Licensee MDPI, Basel, Switzerland. This article is an open access article distributed under the terms and conditions of the Creative Commons Attribution (CC BY) license (http://creativecommons.org/licenses/by/4.0/). 